\title{
O DIÁLOGO TRANSFORMADOR A PARTIR DA Pedagogia da Esperança de Paulo Freire
}

\author{
ERnesto Ferreira GaLLI \\ Fabiana Marini Braga \\ Universidade Federal de São Carlos (UFScar), São Carlos, São Paulo, \\ Brasil
}

\begin{abstract}
Resumo: O presente trabalho trata-se de uma pesquisa bibliográfica que pretendeu responder a um dos objetivos da dissertação de mestrado O diálogo em Paulo Freire: uma análise a partir da "Pedagogia do oprimido" e da "Pedagogia da esperança", referente ao conceito de diálogo na última obra citada. Utilizou-se a metodologia de análise de conteúdo que foi elaborada a partir das palavras e trechos relacionados aos radicais dial. e diál. ao longo de todo o livro. O diálogo na Pedagogia da esperança apresenta características que representam o contexto e a vivência do autor na escrita da Pedagogia do oprimido e da obra aqui tomada como objeto, definindo a grande transformação do mundo por meio da democracia, da unidade na diversidade, da/o professor/a, da consciência, do aprendizado e do silêncio.
\end{abstract}

Palavras-Chave: Diálogo. Democracia. Educação. Unidade na diversidade.

\section{INTRODUÇÃO}

O presente artigo apresenta parte do resultado obtido na dissertação de mestrado intitulada "O diálogo em Paulo Freire: uma análise a partir da Pedagogia do oprimido e da Pedagogia da esperança", em relação à análise do conceito de diálogo desenvolvida na obra Pedagogia da esperança e, com base nesta análise, os conceitos a ele relacionados. 
Paulo Freire é um dos maiores educadores contemporâneos e sua teoria tem influência mundial no campo educacional. Flecha e Puigvert (1998) demonstram isso ao destacar a importância de sua obra mundialmente e o seu encontro com as principais teorias sociológicas:

Freire é o educador contemporâneo mais influente a nível mundial, e como sua importância não para de crescer nos países mais ricos. Basta dedicar 2 a 3 minutos consultando as bases de dados mais significativas da educação (ERIC) e ciências sociais (SOCIOFILE): nos últimos dez anos Freire tem nelas respectivamente 203 e 89 citações [...]. Se chega a mesma conclusão aprofundada nas principais obras de ciências sociais da atualidade (Habermas 1998, Giddens 1995, Beck 1997): todas seguem a mesma perspectiva dialógica de que Paulo Freire foi precursor (FLECHA; PUIGVERT, 1998, p. 22).

Nesse sentido, torna-se cada vez mais relevante estudar esse importante educador brasileiro, que, nas palavras de Gadotti (1996), apresenta uma proposta internacional, transdicisplinar e global, uma vez que "o seu pensamento não se limita à teoria educacional, pois penetra em áreas tão distintas quanto às áreas das ciências sociais e das ciências empírico-analíticas" (GADOTTI, 1996, p. 76). Dessa forma, a teoria de Freire (2003) nos conduz a um mundo marcado por diversas contradições e conflitos, em que as pessoas podem exercer sua liberdade a partir de uma proposta educacional progressista, que, inclusive, foi interrompida pelo exílio do autor em 1964.

Durante sua vida, além de toda a vivência que experimentou e os diálogos que teve no continente africano ao trabalhar no Instituto de Ação Cultural (IDAC), o pensador ganhou influência em diversos países, como Chile, EUA e Suíça, país este no qual residiu por dez anos.

Depois de 16 anos fora de seu país, em 1980, retornou ao Brasil, dedicando-se a reaprender o seu contexto de origem, conforme Torres (1996) argumenta. De um contexto de exílio para um contexto de abertura e volta da democracia, o teórico debruça-se a revisitar alguns de seus conceitos, principalmente o conceito aqui proposto, o de diálogo, chegando a destacar importantes contribuições e avanços em sua produção teórica.

Para Ana Maria de Araújo Freire (2006), a Pedagogia da esperança, escrita em 1992, e resultado de experiências que o autor vivenciou durante o exílio e no seu retorno ao Brasil, apresenta mais maturidade na escrita e no pensamento de Paulo Freire, pois a "vibração com o envolvimento de sua obra Pedagogia do oprimido no mundo, do qual muito se orgulhava, está presente da primeira à última linha, e sua paixão e esperança pelas pessoas e pelo mundo melhor embebem cada uma de suas palavras" (FREIRE, A., 2006, p. 385).

Freire (2008) afirma que os acontecimentos do mundo com grandes complexidades e a retomada da Pedagogia do oprimido foram um movimento 
de maior compreensão de suas tramas e razões, as quais foram refletidas na escrita da Pedagogia da esperança após tantos anos.

\section{Metodologia dA PESQUisa}

O estudo teve como principal base os pressupostos teóricos da pesquisa bibliográfica (LIMA e MIOTO, 2007), que consiste em uma forma de pesquisa que aproxima o objeto a ser estudado por meio de fontes bibliográficas e da análise de conteúdo (BARDIN, 2011).

Importante frisar que, neste artigo, serão apresentados apenas os resultados do livro Pedagogia da esperança, embora, em algumas passagens, seja imprescindível recorrer à obra Pedagogia do oprimido pela relação direta que ambos apresentam entre si.

A análise de conteúdo é um "conjunto de técnicas de análise de comunicações, que utiliza procedimentos sistemáticos e objetivos de descrição do conteúdo das mensagens" (BARDIN, 2011, p.33). Além da descrição das mensagens, colabora com a interpretação delas de uma forma rigorosa, que contempla a delimitação das unidades de codificação ou registro.

A unidade de codificação ou registro compreende "a unidade de significação codificada e corresponde ao segmento de conteúdo considerado unidade de base, visando à categorização e à contagem frequencial" (BARDIN, 2011, p. 134).

Para efeito prático, é realizado um corte semântico que pode corresponder ao tema, o qual pode ser uma palavra, um personagem, um acontecimento, entre outros. O presente trabalho fez uso do tema diálogo e dos radicais dial e diál, que constituíram a unidade base da pesquisa.

Na Pedagogia da esperança, 32 trechos se destacaram, chegando ao seguinte resultado: Aprendizado (radical aprend), Consciência (radical consc), Democracia (radical democr), Professor/a (radical profess), Silêncio e Unidade da diversidade.

Após essa etapa, seguiu-se para o processo de categorização dos dados, que é feita a partir de critérios que podem variar de acordo com a busca e a aproximação do tema, podendo ser semântico, sintático, léxico ou expressivo. A busca desses critérios inicia-se com a investigação do que cada elemento tem em comum com outro (BARDIN, 2011). Dessa forma, a pesquisa utilizou, como critério, as co-ocorrências dos mesmos radicais na relação com o diálogo e por tema abordado.

\section{O diÁlogo na "Pedagogia da esperançA"}

Conforme já mencionado, a análise do conceito foi realizada a partir da busca dos trechos da obra que continham os radicais diál e dial. A partir 
dessa seleção, 32 trechos se destacaram, nos quais os dois radicais repetiamse 42 vezes.

Notou-se que, nesses trechos, algumas palavras importantes na obra freireana apareciam com frequência, chegando-se, então, à seleção das principais palavras associadas ao diálogo, a partir da redução ao seu radical, conforme mostra a tabela abaixo:

Quadro I - Radicais da "Pedagogia da esperança”

\begin{tabular}{|c|c|c|c|}
\hline Redução ao radical & Total & Redução ao radical & Total \\
\hline Educ. & 60 & Pensamento & 6 \\
\hline Dial./Diál & 42 & Pós-modern. & 6 \\
\hline Professor & 22 & Problem & 6 \\
\hline Relaç. & 21 & Consci & 5 \\
\hline Crítica. & 17 & Pergunt. & 5 \\
\hline Pedag. & 17 & Opressor & 4 \\
\hline Oprimido & 16 & Amar/amorosa & 3 \\
\hline Mundo & 13 & Cognosc & 3 \\
\hline Democr. & 12 & Cultura & 3 \\
\hline Alun. & 9 & Dialéti. & 3 \\
\hline Ensin. & 9 & Sonho & 3 \\
\hline Discu. & 8 & Esperança & 2 \\
\hline Prática & 8 & Liber. & 2 \\
\hline Autorit. & 7 & Liderança & 1 \\
\hline Silêncio & 7 & Pronúncia & 1 \\
\hline Aprend. & 6 & & \\
\hline Conhecimento & 6 & & \\
\hline Conteúdo & 6 & & \\
\hline Experiência & 6 & & \\
\hline Idealis & 6 & & \\
\hline
\end{tabular}

Ao considerar essas palavras como ponto de partida, realizou-se a leitura dos trechos com foco na relação entre o conceito de diálogo e as palavras e os conceitos por ela nomeados apresentados no trecho.

Entretanto, ao iniciar a análise, percebeu-se, na leitura de alguns trechos, que a forma de escrita não apresentava uma relação direta do diálogo com esses conceitos, mas sim em forma de discussão ou debate com outra(s) pessoa(s): 
Exemplo 1:

As tramas, os fatos, os debates, discussões, projetos, experiências, diálogos de que participei nos anos 70, tendo a Pedagogia do oprimido como centro, me parecem tão atuais quanto outros a que me refiro dos anos 80 e de hoje (FREIRE, 2008, p. 13).

Exemplo 2:

O segundo encontro que me impressionou na primeira visita foi o que tive com funcionários administrativos do Ministério da Educação. O Ministério reservou uma manhã para o nosso diálogo, para o qual foram todos convidados, desde os serventes e motoristas até as secretárias dos diferentes departamentos, passando pelas datilógrafas (FREIRE, 2008, p. 169).

Com isso, dentre os 32 trechos, foram selecionados 16 que apresentaram especificamente conceitos relacionados à definição de diálogo, a saber: Aprendizado, Consciência, Democracia, Professor/a, Silêncio e Unidade da diversidade. Inicialmente, serão apresentados os primeiros 16 trechos cujos diálogos retratam o encontro de Freire (2008) com outras pessoas, para, na sequência, serem aprofundados os elementos constitutivos do diálogo.

\subsection{Dí́lOGOS COM O PASSADO}

Esta apresentação inicia-se a partir do diálogo que Freire (2008) fez com suas memórias, em que se sobressaem momentos impactantes na escrita da Pedagogia do oprimido e na Pedagogia da esperança.

Para facilitar a apresentação dos dados, os trechos foram agrupados a partir de alguns pontos comuns entre eles, sendo, no entanto, apresentados apenas alguns como exemplo de cada situação. Dessa forma, chegou-se à seguinte separação: trecho introdutório, trechos que contêm diálogos entre o autor e pessoas envolvidas com a prática do dia a dia, trechos que trazem a discussão sobre a diversidade da linguagem, trechos referentes ao diálogo com militantes e, por último, trechos referentes às críticas realizadas pelo próprio teórico.

\subsubsection{INTRODUÇÃO}

O primeiro trecho da obra em que aparece a palavra diálogo refere-se ao terceiro momento da Pedagogia da esperança em que o autor explicita que dialogou, entre os anos de 1970 e 1980, com diversas pessoas que tiveram a oportunidade de vivenciar a leitura e a prática da Pedagogia do oprimido, escrita anos antes. 
As tramas, os fatos, os debates, discussões, projetos, experiências, diálogos de que participei nos anos 70, tendo a Pedagogia do oprimido como centro, me parecem tão atuais quanto outros a que me refiro dos anos 80 e de hoje (FREIRE, 2008, p. 13).

Com isso, a discussão apresentada na Pedagogia da esperança ainda é considerada atual. E foi a partir do diálogo que Freire (2008) conseguiu visualizar a importância da Pedagogia do oprimido, mesmo no início da década de 1990.

\subsubsection{LEMBRANÇAS DA PRÁTICA}

Em relação às lembranças da prática, Freire (2008) retoma as lembranças dos diálogos com pessoas envolvidas com sua prática cotidiana e que influenciaram a escrita da Pedagogia do oprimido.

Em relação ao diálogo, nesse caso, o autor assinala que o manteve com intelectuais brasileiros, com camponeses, com pescadores, com momentos de sua vida, ou seja, com uma diversidade de pessoas e situações que trouxeram contribuições para o seu pensamento, como explicitado abaixo:

Minhas longas conversas com pescadores em suas caiçaras na praia de Pontas de Pedra, em Pernambuco, corno meus diálogos com camponeses e trabalhadores urbanos, nos córregos e morros do Recife, não apenas me familiarizaram com sua linguagem mas também me aguçaram a sensibilidade à boniteza com que sempre falam de si, até de suas dores, e do mundo. Boniteza e segurança também (FREIRE, 2008, p. 69).

Alguns dos momentos relevantes dizem respeito à sua preocupação com a participação de pais, mães, estudantes e funcionários do SESI em todas as atividades.

Do mesmo modo, as aulas também foram motivo de reflexão para o autor, que sempre se mostrou atento para apresentar diferentes visões, considerar e estimular a fala dos educandos e educandas. Assim, pode-se notar que, partindo dos diferentes diálogos, Freire (2008) já explicitava uma reflexão em sua prática sobre a valorização do saber da experiência proveniente dos educandos.

\subsubsection{DiVERSIDADE LINGUÍSTICA}

Nesta parte da análise, percebe-se que a reflexão sobre a questão da diversidade da linguagem é essencial para o diálogo, como é possível constatar nesta passagem: 
Foi repetindo o caminho tradicional do discurso sobre, feito aos ouvintes, que passei ao debate, à discussão, ao diálogo em torno do tema com os participantes [...]. Disse quase porque, na verdade, minha sensibilidade já me havia advertido quanto às diferenças de linguagem, as diferenças sintáticas e semânticas, entre a dos operários e operárias com quem trabalhava e a minha linguagem (FREIRE, 2008, p.24).

Nesse sentido, Freire (2008) retoma seu trabalho no SESI, com a realização de uma série de palestras sobre sua pesquisa que abordou a relação entre os pais e mães e seus filhos e filhas, relembrando as reuniões que fazia com os pais dos educandos. A sua fala caracterizava-se por uma linguagem acadêmica, pois o autor pensava em uma palestra e não em um diálogo. Mas, no momento de interação, foi possível perceber a diferença entre a linguagem que ele utilizava e a linguagem dos participantes da palestra.

O pensador destaca que não considerava plenamente as diferenças que muitas vezes dificultam o diálogo. Por isso, apesar de falarem a mesma língua, naquele momento, para estabelecer o diálogo, foi substancial considerar as pequenas diferenças.

Dessa forma, o diálogo com os participantes foi fundamental para pensar a valorização da leitura de mundo das pessoas e a consideração de seus conhecimentos, elementos presentes na Pedagogia do oprimido.

\subsubsection{DIÁLOGO COM MILITANTES}

O diálogo com os militantes possibilitou, ao autor, visualizar a influência de sua teoria na vida dessas pessoas e como se apresentava na prática, as dificuldades e as realizações executadas por elas.

Desse modo, foi a partir dos diálogos com essas pessoas que Freire (2008) reconheceu a extensão de sua teoria em suas vidas, ao dialogar sobre as relações opressoras, a necessidade do diálogo e de uma educação problematizadora, como destacado a seguir:

Esta foi uma satisfação - a de, sendo um pensador da prática educativa, ter sido compreendido e convidado por militantes em luta, ao diálogo em torno de sua própria luta, armada ou não, que me acompanhou por toda a década de 70 e se prolonga até hoje, com minha visita a El Salvador de que falo no fim deste livro (FREIRE, 2008, p.149).

No contato com essas pessoas, Freire (2008) percebeu a importância que tinha a sua proposta de educação para a vida delas. Motivo este que somente fazia crescer o número de visitas que o autor recebia para dialogar. 
Em suas viagens pelo mundo, Freire (2008) chegou a refletir sobre seu aprendizado, sendo uma delas, especificamente, na Tanzânia e na Zâmbia, em que lhe foi possível observar a forte presença do racismo, ao ver que negros eram igualados a animais (FREIRE, 2008). Essa vivência levou-o a pensar na efetiva necessidade de construir uma sociedade mais igualitária a partir daquilo que ele denominou de unidade na diversidade.

Em diversos meios, procurou escutar a todos e convidar as pessoas presentes a dialogar, reforçando um posicionamento democrático.

A perspectiva democrática foi um dos aprendizados positivos que o autor vivenciou na prática. Não obstante, os diálogos com os militantes também apresentaram desafios a serem superados. Dessa forma, esses trechos referem-se fortemente à possibilidade que o autor teve ao considerar o diálogo como perspectiva de aprender com as outras pessoas.

\subsubsection{CRÍTICAS AO DIÁLOGO}

Apesar de ter recebido diversas críticas pela Pedagogia do oprimido, Freire (2008) encarou-as de forma dialógica, pois as compreendia como críticas que contribuem para o aprendizado e não como ofensas. O diálogo envolve o respeito à opinião, envolve a escuta, envolve o silêncio, considerando a fala de todas as pessoas, por mais diferentes que sejam. Dessa forma, as críticas são encaradas como contribuição quando se referem ao diálogo. Assim, a partir das críticas, o autor teve a oportunidade de reforçar seus conceitos e de rever alguns pontos, buscando refletir a partir de questões levantadas por outras pessoas, como exposto no trecho abaixo:

Obviamente, recusava, ontem como hoje, um tal tipo de crítica. Os debates, porém, jamais perderam o tom do diálogo, jamais viram polêmica. No fundo, as pessoas dissentiam de mim mas não me queriam mal. Suas críticas não se nutriam de uma raiva incontida de mim (FREIRE, 2008, p.181).

Portanto, a ideia da crítica reforça a dialogicidade da relação, pois abre a perspectiva para o aprendizado a partir das diferenças, visto que a crítica foi realizada por pessoas com diferentes perspectivas. Estes foram os momentos em que Freire (2008.) priorizou as memórias, para, então, dialogar com elas e elaborar seu pensamento.

\subsection{Os elementos do diálogo na "Pedagogia da esperança"}

Conforme já apresentado, dentre os 32 trechos selecionados, 16 apresentaram aspectos relacionados à definição de diálogo. Neste trabalho, serão destacados, a título de exemplo, alguns desses trechos. 
Por fim, o conceito de antidiálogo também será abordado, embora não apareça nesses termos na Pedagogia da esperança, mas como tema em um dos trechos selecionados.

\subsubsection{Democracia}

A democracia é um conceito presente em diversos momentos do livro a partir das lembranças e dos trabalhos e diálogos realizados, como é possível observar no seguinte trecho: "enquanto relação democrática, o diálogo é a possibilidade de que disponho de, abrindo-me ao pensar dos outros, não fenecer no isolamento" (FREIRE, 2008, p. 119-120).

A relação democrática estabelece-se de duas formas: o diálogo é uma forma de garantia da democracia; e a relação dialógica é democrática, ou seja, o diálogo é democrático.

Freire (2008) indica que o estabelecimento do diálogo com as famílias dos educandos e das educandas garante oportunidades de participação democrática na escola. Assim, a relação dialógica proporciona uma maior participação democrática, uma vez que as famílias são escutadas e podem contribuir com seus conhecimentos e sua realidade. A democracia está relacionada diretamente com a possibilidade e a capacidade de todos terem o mesmo valor de fala. Dessa forma, a participação de todas as pessoas tem de ser valorizada e incentivada, pois, para o autor, todos os conhecimentos são válidos e merecem ser considerados em uma relação dialógica.

Ao considerar a fala de todas as pessoas, estas aprendem umas com as outras, considerando o que sabem e o que os outros sabem. Nesse sentido, a relação dialógica promove o aprendizado e favorece o estabelecimento de uma relação democrática no âmbito do sujeito. Em relação ao mundo estrutural, a relação dialógica contribui para a implantação da democracia como política.

Nesse sentido, Giroux (1997) proporciona uma consistente discussão sobre o processo de democratização e transformação do ensino, ressaltando a importância de tornar o pedagógico mais político e vice-versa. Ou seja, de destacar as escolas como espaço político, buscando estimular seus estudantes a desenvolverem uma reflexão e ação crítica a partir do diálogo, tendo em vista a construção de uma sociedade melhor para todas as pessoas. Nesse sentido, há que se destacar ainda o papel político dos professores, que, segundo o autor, passam a ser considerados como intelectuais transformadores em favor da mudança e da possibilidade. 


\subsubsection{SILÊNCIO}

O silêncio é um dos elementos que aparecem no livro na ocasião em que Freire (2008) relata seu diálogo com camponeses chilenos, no qual ocorreu um momento significativo de silêncio, como é apresentado no trecho:

O que não teria sentido é que eu "enchesse" o silêncio do grupo de camponeses com minha palavra, reforçando assim a ideologia que já haviam explicitado. O que eu teria de fazer era partir da aceitação de alguma coisa dita no discurso do camponês e, problematizando-os, trazê-los ao diálogo de novo (FREIRE, 2008, p.47).

A partir da experiência do diálogo com camponeses chilenos, o autor compreende a importância do silêncio em uma relação dialógica, rompendo com a ideia de que o silêncio é um vazio sem ausência de sentido. Ao contrário, durante o diálogo silencioso com os camponeses, o autor pôde entender como a relação entre as duas partes - camponeses e educador estava ocorrendo.

Durante o silêncio, Freire (2008) conseguiu pensar e refletir sobre a situação. Ao problematizá-la, junto ao seu direito à fala, a postura do autor partiu da perspectiva do diálogo e da transformação das relações com os camponeses. Naquele momento, a relação dialógica estabeleceu-se mediante o silêncio.

É importante ressaltar que, caso o teórico tivesse desconsiderado o silêncio, romperia a possibilidade de estabelecer uma relação dialógica. O silêncio, portanto, é um importante momento do diálogo que propicia reflexão sobre sua própria estrutura e as relações nele estabelecidas.

Em seu livro Filosofia da libertação, Dussel (1977) mostra a categoria de "exterioridade" do "outro", ressaltando que "o direito do outro, fora do sistema, não é um direito que se justifique pelo projeto do sistema ou por suas leis. Seu direito absoluto, por ser alguém, livre, sagrado, funda-se em sua própria exterioridade, na constituição real de sua dignidade humana"(DUSSEL, 1977, p.49). Assim, o outro, o qual é silenciado pelo sistema vigente, necessita ser respeitado, mas não como alguém que nada tem a dizer, e sim aquele que tem de reconstruir sua liberdade a partir de sua realidade oprimida.

\subsubsection{CONSCIÊNCIA}

A consciência é um tema discutido na Pedagogia da esperança, principalmente por retomar a discussão feita na Pedagogia do oprimido, obra em que esse conceito aparece com muita ênfase, como no trecho: 
Do ponto de vista do dogmatismo mecanicista, não temos como sequer falar em conscientização. Daí que as lideranças dogmáticas, autoritárias, não tenham por que dialogar com as classes populares, mas dizer-lhes o que devem fazer (FREIRE, 2008, p.105).

A relação consciência-mundo é muito importante para o autor, uma vez que sua compreensão de forma dialógica é essencial para transformação. Consciência e mundo relacionam-se e influenciam um ao outro. Nesse sentido, Freire (2008) faz críticas tanto a uma compreensão idealista quanto a uma mecanicista:

Mas, dialoguei também com quem, preso ao dogmatismo igualmente de origem marxista, mais do que minimizava a consciência, a reduzia a pura sombra da materialidade. Para quem pensava assim, mecanicistamente (FREIRE, 2008, p.179).

Uma posição idealista defende a transformação da consciência como essencial, sem, necessariamente, transformar a realidade, uma vez que nessa visão o mundo é um reflexo da consciência. Já na posição mecanicista, o papel central no processo de conscientização é responsabilidade de uma liderança que tem a função de indicar o caminho, negando-se, logo, ao diálogo e valorizando um grupo já consciente.

Assim, Freire (2008) enfatiza que os educadores precisam trabalhar a relação entre "leitura do mundo" e "leitura da palavra" a partir do reconhecimento dos saberes de experiência das pessoas, de modo a refletir e problematizar junto com elas o seu mundo e ao outro. Como nos lembra Dussel (1977, p.100), “a libertação do oprimido é realizada pelo oprimido, mas por mediação da consciência crítica do mestre, o condutor: o intelectual orgânico, com o povo e no povo". Sob esse ponto de vista, todo esse trabalho envolve o diálogo entre as pessoas e, nesse processo, consciência e mundo vão se transformando mutuamente na ação e na reflexão das pessoas:

Em coerência com a posição dialética em que me ponho, em que percebo as relações mundo-consciência-prática-teoria-leitura-do-mundo-leitura-da-palavra-contexto-texto, a leitura do mundo não pode ser a leitura dos acadêmicos imposta às classes populares. Nem tampouco pode tal leitura reduzir-se a um exercício complacente dos educadores e educadoras em que, como prova de respeito à cultura popular, silenciem em face do "saber de experiência feito" e a ele se adaptem (FREIRE, 2008, p. 106-107).

Assim, por meio da leitura de mundo e da leitura da palavra, e da compreensão de que a consciência compreende a transformação da realidade e estabelece uma relação direta com o mundo, é que pode surgir a práxis crítico-transformadora, superando a visão das duas compreensões. 


\subsubsection{PROFESSORA/PROFESSOR}

Em relação aos professores e professoras, o autor aponta algumas considerações feitas sobre como a relação dialógica contribui para os professores e professoras em sua relação com os estudantes, como destacado no trecho:

O diálogo, na verdade, não pode ser responsabilizado pelo uso distorcido que dele se faça. Por sua pura imitação ou sua caricatura. O diálogo não pode converter-se num "bate-papo" desobrigado que marche ao gosto do acaso entre professor ou professora e educandos (FREIRE, 2008, p. 118).

Freire (2008) reitera que a relação pedagógica entre professores/as e estudantes precisa ter o diálogo como centro, pois isso favorece o aprendizado de todas as pessoas envolvidas, visto que o objeto a ser apreendido não se encerra na cognição de uma única pessoa, mas sim de todas as pessoas que têm a possibilidade de apreendê-lo. Mas, para isto, o diálogo entre os dois precisa ser compromissado e não licencioso ou se tornar um mero bate-papo, ou um depósito de conteúdos. Assim, cabe aos professores e às professoras envolvidos na relação pedagógica a responsabilidade de estar atentos aos princípios que garantem a dialogicidade e o respeito às falas de todas as pessoas e, portanto, contribuir para o aprendizado dos estudantes. Isso sugere que, como intelectuais transformadores, os/as professores/as deverão assumir a necessidade de reconhecer a voz dos/as estudantes e desenvolver uma linguagem crítica diante dos problemas da realidade cotidiana, de forma que percebam que podem gerar mudanças para a construção de uma melhor sociedade para todos (GIROUX, 1997).

\subsubsection{ApRENDIZADO}

O aprendizado também foi um dos temas relacionados ao diálogo discutido na Pedagogia da esperança (2008). O tema está diretamente pautado na relação entre professores, professoras e estudantes, que em alguns momentos se mesclam. $O$ aprendizado também se reflete em outros pontos apresentados:

Não há diálogo no espontaneísmo como no todo-poderosismo do professor ou da professora. A relação dialógica, porém, não anula, como às vezes se pensa, a possibilidade do ato de ensinar [...]. O diálogo pedagógico implica tanto o conteúdo ou objeto cognoscível em torno de que gira quanto a exposição sobre ele feita pelo educador ou educadora para os educandos (FREIRE, 2008, p.118). 
Nesse tópico, o autor apresenta críticas ao espontaneísmo com que professores e professoras muitas vezes lidam com os estudantes, favorecendo a licenciosidade das aulas. Sua principal ênfase está no fato de que, em uma relação pedagógica, o diálogo precisa ser pedagógico, posto que tem a intenção de ensinar conteúdos.

O diálogo pedagógico possibilita que os estudantes encarem o objeto por diferentes possibilidades, desenvolvendo o pensamento crítico sobre a realidade. Isso é possível por meio do diálogo, que busca a problematização dos temas e considera as diferentes percepções. Esse último aspecto relacionase com o fato de que a diversidade, ao trazer a contribuição de diferentes realidades, potencializa o aprendizado.

Dessa forma, a relação pautada em ações espontâneas não leva ao aprendizado, limitando-se à conversa sem sentido nem finalidade, impossibilitando o diálogo. Por isso, os professores e professoras precisam se dedicar ao diálogo na preparação de suas aulas e no ensino dos conteúdos.

Freire (2008) também tece suas considerações sobre a estrutura da aula, salientando que uma aula expositiva pode ser dialógica, na medida em que pode contribuir com a visão crítica dos estudantes e considerar suas falas na própria exposição. $O$ critério importante para garantir a dialogicidade é pensar na relação a ser estabelecida, que deve ser dialógica. Se professores e professoras conseguirem estabelecer isso com os estudantes, o formato apenas fortalecerá o processo educativo.

\subsubsection{UNIDADE NA DIVERSIDADE}

A unidade na diversidade é um dos temas abordados no livro. $\mathrm{O}$ contexto em que aparece se refere a um diálogo realizado por Freire (2008) em um seminário em Chicago, nos Estados Unidos, do qual participaram vários grupos culturais. No início dessa conversa, muitas lideranças dos grupos presentes posicionaram-se, afirmando sua identidade e seu desejo de se relacionarem apenas com o seu grupo cultural. Cabe destacar que somente os brancos não se manifestaram:

"Não, esta não é uma afirmação branca", disse eu. “É uma afirmação lúcida e progressista que poderia ter sido feita por um homem negro, por uma mulher negra, por um irlandês de olhos azuis, por um chicana, não importa por quem, desde que progressista. Esta afirmação só não pode ser feita por uma pessoa interessada em manter o status quo, só não pode ser feita, coerentemente, por um racista. O que é possível, porém, é que, historicamente, não haja, agora, possibilidade por $\mathrm{n}$ razões, de realizar-se a unidade na diversidade. Que as bases de cada 'minoria', por exemplo, não tenham 
amadurecido o suficiente ainda para aceitar o diálogo, o estar com, entre elas ou, o mais provável, suas lideranças. Isto é outra coisa. Dizer, porém, que a unidade na diversidade é, em si, 'uma afirmação branca', não. Não é correto" (FREIRE, 2008, p.154).

A unidade na diversidade é um dos conceitos mais importantes dessa obra, e o autor aborda o tema em várias de suas obras posteriores à Pedagogia da esperança.

Como destacado anteriormente, a unidade na diversidade compreende um conceito que valoriza a diversidade em que vivemos, considerando os diferentes grupos com os quais compartilhamos o mundo: os indígenas, os negros, os brancos, os latinos, etc. Mas, indo além, Freire (2008) destaca que, apesar das diferenças, é possível estabelecer o diálogo entre esses grupos de forma que eles não vivam isolados, mas compartilhando conhecimentos, vivências, experiências. Nesse contexto, seria possível a transformação da realidade para a construção de um mundo mais justo para todos e todas, sem ferir ou desrespeitar as diferenças culturais.

Assim, a possibilidade do diálogo é reforçada pelo autor nesses trechos, pois é por meio dele que é possível garantir o respeito às diferentes formas de viver, bem como a possibilidade de compartilhar conhecimentos.

O diálogo entre diferentes é ressaltado em vários momentos nessa obra e favorece o aprendizado, a perspectiva democrática, a transformação da consciência e do mundo em que vivemos. Isso tudo atua no sentido de estabelecimento de uma unidade, ou seja, algo que nos une, na diversidade em que vivemos.

Freire (2008) deixa claro que as posições diversas são reforçadas durante o diálogo entre os diferentes e, que dessa forma, seria possível a superação de posições sectárias para a consolidação de uma perspectiva democrática, como destacado pelo autor:

O aprendizado, afinal, de que, numa nova prática democrática, é possível ir ampliando os espaços para os pactos entre as classes e ir consolidando o diálogo entre diferentes. Vale dizer, ir aprofundando-se as posições radicais e superando-se as sectárias (FREIRE, 2008, p.198).

A unidade na diversidade é um ponto muito importante para compreender a perspectiva do diálogo. Pois é a diversidade que amplia a necessidade do diálogo e que possibilita uma transformação significativa nas pessoas e no mundo, visto que inclui perspectivas diferentes que são estabelecidas juntas entre os diferentes grupos, bem como a transformação ética que, segundo Santos (2003), caracteriza-se pela luta pelo direito de 
sermos iguais diante das diferenças que nos inferiorizam e pelo direito de sermos diferentes naquilo que a igualdade nos descaracteriza.

Por fim, estes são os pontos essenciais que aparecem na Pedagogia da esperança relacionados ao diálogo. Pode-se perceber que todos influenciam e garantem a relação dialógica. O próximo item dedica-se à apresentação do conceito do antidiálogo que contrapõe esses pontos, sendo muito importante para a compreensão do próprio conceito de diálogo, objetivo central deste artigo.

\subsection{Antidiálogo}

O termo antidiálogo especificamente não aparece em nenhum momento do livro. Mas em um dos trechos, em determinada situação, surge a negação do diálogo por meio de posturas autoritárias, como destacado no trecho a seguir:

O caminho para as forças progressistas mais à esquerda da Democracia Cristã estaria em aproximar-se dela - política é concessão com limites éticos - cada vez mais, não para dominá-la, evitando que dela se aproximasse para esmagá-la a direita, nem tampouco para a ela se converter. Por sua vez, a Democracia Cristã, intolerantemente, se negava ao diálogo Não havia credibilidade, nem de um lado nem do outro (FREIRE, 2008, p.39-40).

O contexto do qual trata o trecho em destaque refere-se a uma situação que Freire (2008) viveu no Chile, durante os anos de 1964 e 1970, sob o governo do presidente Eduardo Nicanor Frei Montalva. Em determinado momento, o Partido da Democracia Cristã demonstrou-se contrário a sua obra, afirmando que ela representava um documento contra o então presidente Frei. Esse período foi delicado e dificultou a situação de Freire no país.

A partir de suas reflexões, Freire considera que a posição tomada pelo partido na época foi antidialógica, pois negou a possibilidade de conversa. Além disso, foram apresentadas acusações que demonstravam uma posição contrária à teoria de Paulo Freire. Nesse sentido, o diálogo foi negado em prol de uma perspectiva autoritária. Apesar de a perspectiva antidialógica não ser apresentada diretamente nessa obra, no caso deste trecho ela fica visível, por estar explícita em determinada situação. Cabe enfatizar que o autor não utiliza o termo, sendo possível que tenha superado esse conceito.

\section{CONCLUSÃO}

A partir dos dados coletados, foi possível compreender o conceito de diálogo na Pedagogia da esperança e a transformação que ocorreu nos 
22 anos de distância entre esta obra e a Pedagogia do oprimido. Do mesmo modo, pôde-se ver como o contexto influenciou o autor.

Nesse sentido, constatou-se que, apesar de os conceitos serem apresentados separadamente, os elementos acima apresentados mesclam-se de diversas formas e se relacionam entre si. O diálogo é um ponto comum entre todos eles e, por isso, sua fragmentação é apenas metodológica.

Um elemento de destaque diz respeito ao conceito de democracia, pois, ao incluir em sua teoria a perspectiva democrática, o autor está reconhecendo o saber das pessoas, a sua leitura de mundo e a reflexão sobre determinada realidade, princípio básico do diálogo. Essa visão reforça ainda a compreensão de que todos e todas têm algo a contribuir e algo a aprender a partir da sua própria diversidade, além de considerar a radicalidade da democracia, ao pensá-la por meio do diálogo.

Dessa forma, a aprendizagem e a unidade da diversidade também são elementos que permeiam os dois momentos de análise dessa obra, pois, somente a partir do diálogo com diferentes pessoas, Paulo Freire teve condições de pensar e repensar elementos de sua teoria. Isso porque, ao dialogar com outras pessoas, a intersubjetividade e a intercomunicação se fizeram presentes, possibilitando a ele novas aprendizagens.

As professoras e os professores têm de fazer parte do conceito de diálogo por serem as pessoas que o exercem na escola com os estudantes e as estudantes. No entanto, isso só é possível a partir do reconhecimento de que é possível a leitura de mundo e a leitura da palavra, como destacado no aspecto da consciência. E, por fim, o diálogo se compõe a partir da escuta que se dá pelo silêncio.

Cabe destacar que estes são elementos presentes na Pedagogia da esperança relacionados ao diálogo, mas essa ocorrência não se dá de forma clara durante a obra. Esses elementos, em sua maioria, apareceram relacionados a outros elementos e lembranças que contribuem para a sua compreensão. Isso apenas reforça o diálogo como um meio que viabiliza toda a discussão realizada pelo autor com as outras pessoas. Assim, o diálogo torna-se o cerne de todas as relações que Freire estabeleceu com mundo e com as pessoas para poder pensar sobre si próprio e sobre o mundo. Ou seja, é a própria transformação da realidade, pois entrelaça o sujeito com o mundo em que vive e a possibilidade de transformar o mundo, sendo dialógico. 
THE TRANSFORMER DIALOGUE FROM THE PEDAGOGY OF HOPE OF PAULO FREIRE

ABSTRACT: This work is characterized by a bibliographic research which intended to respond to one of the master's thesis objectives Dialogue on Paulo Freire: an analysis from the Pedagogy of the Oppressed and hope Pedagogy, referring to the concept of dialogue in Pedagogy hope. For its realization was used content analysis methodology that was held from the words and passages that related to the dial and dial radicals throughout the work. The dialogue in Pedagogy of Hope has characteristics that represent the context and the experience of the author in writing of Pedagogy of the oppressed and the work here addressed, defining itself as the great transformation of the world through democracy, unity in diversity, the teacher, consciousness, learning and silence.

KeYWORDS: Dialogue. Democracy. Education. Unity in diversity.

\section{EL DIÁLOGO TRANSFORMADOR DE LA PEDAGOGÍA DE LA ESPERANZA DE PAULO FREIRE}

RESUMEN: Este trabajo es una investigación bibliográfica que buscó responder a uno de los objetivos de la tesis de maestría "Diálogo en Paulo Freire: un análisis desde la Pedagogía del oprimido y la Pedagogía de la esperanza", sobre el concepto de diálogo en Pedagogía la esperanza. Para su desarrollo se utilizó la metodología de análisis del contenido que se elaboró a partir de las palabras y pasajes relacionados a los radicales de marcación dial y diál a lo largo de esa obra. El diálogo en Pedagogía de la esperanza tiene características que representan el contexto y la experiencia del autor en cuando escribió Pedagogía del oprimido y de la obra que aquí se ha tomado como objeto, definiendo la gran transformación del mundo a través de la democracia, de la unidad en la diversidad, del maestro y de la maestra, de la conciencia, del aprendizaje y del silencio.

Palabras Clave: Diálogo. Democracia. Educación. Unidad en la diversidad.

\section{REFERÊNCIAS}

BARDIN, L. Análise de conteúdo. São Paulo: Edições 70, 2011.

DUSSEL, E. Filosofia da libertação. São Paulo: Edições Loyola: Editora Unimep, 1977.

FLECHA, R.; PUIGVERT, L. Aportaciones de Paulo Freire a la educación y las ciencias sociales. Revista interuniversitaria de formación del profesorado, Espanha, n. 33, 1998.

FREIRE, A. M. A. Paulo Freire: uma história de vida. Indaiatuba (SP): Villa das Letras, 2006. 
. Pedagogia do oprimido. 36. ed. Rio de Janeiro: Paz \& Terra, 2003.

. Pedagogia da esperança: um reencontro com a pedagogia do oprimido. 15. ed. Rio de Janeiro: Paz \& Terra, 2008.

GADOTTI, M. Paulo Freire: uma biobibliografia. São Paulo: Cortez Editora, 1996.

GIROUX, H.A. Professores como intelectuais transformadores. In: GIROUX, H.A. Os professores como intelectuais. Rumo a uma pedagogia crítica da aprendizagem. Porto Alegre: Artes Médicas, 1997, p. 157-164.

LIMA, T. C. S.; MIOTO, Regina. C. T. Procedimentos metodológicos na construção do conhecimento científico: a pesquisa bibliográfica. Revista Katálisis, Florianópolis, v. 10, p. 37-45, 2007.

SANTOS, B. S. Direitos e diversidade. Conferência proferida no III Fórum Social Mundial de Porto Alegre, 25 de janeiro de 2003.

TORRES, C. A. A voz do biógrafo latino-americano: Uma biografia intelectual. In: GADOTTI, M. Paulo Freire: uma biobibliografia. São Paulo: Cortez Editora, 1996.

ERnesto Ferreira Galli é doutorando do Programa de Pós-Graduação em Educação na Universidade Federal de São Carlos (UFSCar), mestre em Educação (UFSCar) e graduado em Pedagogia (UFSCar).

E-mail: efgalli@gmail.com

Fabiana Marini Braga é professora adjunta do Departamento de Teorias e Práticas Pedagógicas da Universidade Federal de São Carlos (DTPP/UFSCar) e doutora em Educação (UFSCar).

E-mail: fabiana@ufscar.br 